\title{
PULMONARY FUNCTION CHANGES AFTER BRONCHOSCOPIC BIOLOGICAL LUNG VOLUME REDUCTION THERAPY USING AUTOULOGOUS BLOOD
}

\author{
Mostafa Bakeer ${ }^{1}$, Taha Abd El-Gawad ${ }^{1}$, Raed El-Metwally Ali ${ }^{1}$, Ahmed Saad \\ El-Morsi ${ }^{1}$, Mohammad El-Badrawy ${ }^{1}$, Solafa El-Sharawy ${ }^{2}$ \\ 1. Chest Medicine, Faculty of Medicine, Mansoura University, Mansoura, Egypt. \\ 2. Clinical Pathology, Faculty of Medicine, Mansoura University, Mansoura, \\ Egypt.
}

\begin{abstract}
Background: Bronchoscopic lung volume reduction (BLVR) using biological agents is one of the new alternatives to lung volume reduction surgery.

Objectives: To evaluate the potential efficacy of bronchoscopic biological lung volume reduction using autologous blood injection in pulmonary emphysema patients.

Methods: 7 male patients were enrolled in the study. After determining the targeted emphysematous segment by high resolution computerized tomography (HRCT), $30 \mathrm{ml}$ autologous blood was injected via balloon catheter over 10 to 15 seconds into the targeted segment and left in position for 3-6 minutes allowing time for blood to coagulate. The bronchoscope was then repositioned at the following targeted segment. Changes in residual volume (RV), residual volume to total lung capacity ratio (RV/TLC), forced expiratory volume in one second (FEV1) and forced expiratory volume to forced vital capacity ratio (FEV1/FVC) were evaluated at 12-week post procedure as well as for complications.

Results: At 12-week post procedure there was statistically significant reduction in $\operatorname{RV} / \mathrm{TLC}(p=0.038)$. FEV1 significantly increased $(p=0.018)$. In addition, there was significant improvement in FEV1/FVC $\%(p$ $=0.003)$. All cases tolerated the procedure with no mortality. There was one case that developed pneumonia at the same side of intervention, and two cases developed mild haemoptysis (blood streaked sputum). There was no life threatening complications e.g (pneumothorax, pulmonary embolism, cardiac ischaemia or myocardial infarction) occurred htoughout the study.

Conclusion: Bronchoscopic lung volume reduction using autologous blood injection could be an effective, cheap and relatively safe method to treat advanced emphysema in comparison to other agents used in the clinical trials.
\end{abstract}

Keywords: Emphysema; Bronchoscopy; Lung volume reduction.

\section{INTRODUCTION}

E mphysema is a chronic and progressive disease, characterized by abnormal permanent enlargement of air spaces distal to the terminal bronchioles. ${ }^{1}$

The clinical usefulness of bronchoscopic techniques for achieving lung volume reduction has been studied in patients with advanced emphysema as these procedures are considered to be safer than surgical volume reduction. ${ }^{2}$

Biological lung volume reduction is a new bronchoscopic approach that uses biological agents aiming to reduce lung volume by blocking off the most emphysematous areas with a rapidly polymerizing sealant. The mechanism of action involves resorption atelectasis from airway occlusion, subsequent airspace inflammation, and then remodeling. This remodeling will lead to scarring that induces contraction of lung parenchyma and functional volume reduction can be expected within 6-8 weeks. ${ }^{3}$ Biological lung volume reduction occurs independent of the presence or absence of collateral ventilation. ${ }^{2}$

\section{AIM OF THE WORK}

The aim of this study is to evaluate the potential efficacy of bronchoscopic biological lung volume reduction using autologous blood injection in pulmonary emphysema patients.

\section{PATIENTS AND METHODS}

This study was carried out in Chest Medicine Department in collaboration with Clinical Pathology Department, Mansoura University Hospital. Seven patients with heterogeneous emphysema were enrolled, and all patients provided written informed consent prior to participation.

\section{$>$ Study population: \\ Inclusion criteria:}

1. Heterogenous emphysema determined by HRCT of the chest plus: 
(a) FEV1 $/$ FVC $<70 \%$ and FEV1 20- $50 \%$

(b) Hyperinflation: total lung capacity (TLC) $\geq 110 \%$ pred and residual volume/ total lung capacity (RV/TLC) $\geq 120 \%$ pred.

2. Patients not candidate for or had refused LVRS.

3. Age $>40 \mathrm{yrs}$.

Exclusion criteria:

1. Airflow limitation with FEV $1<20 \%$.

2. DLCO $<20 \%$.

3. Current smoker.

4. Patients not candidate for FOB.

\section{Study design:}

All selected patients were subjected to the following:

$\square$ Thorough history taking and clinical examination.

$\square$ Routine investigations including: Chest $\mathrm{X}$ ray, Complete blood picture, prothrombin time, INR, liver and kidney function tests, electrocardiogram and arterial blood gases analysis.

Pulmonary function tests were done on admission as a basic value, then at 12 week post procedure including:

- RV, RV/TLC ratio, using single breath helium dilution method.

- Spirometry (FEV1, FEV1/FVC ratio).

\section{Post procedure evaluation:}

All patients were monitored for 24 hour post procedure for the development of any early complications e.g. (COPD exacerbations, pneumothorax, pulmonary embolism, cardiac ischaemia or myocardial infarction) and also monitored during the follow up period for the development of late complications e.g. (pulmonary abscess and empyema).

\section{$>$ Outcomes evaluation:}

(A) The primary end-point:

Reduction in the volume of the targeted emphysematous part, at 12 weeks post procedure, detected by reduction in $\mathrm{RV} / \mathrm{TLC}$ ratio from baseline.

(B) The secondary end-points:

(1) Changes from baseline at 12 weeks in FEV1 and FEV1/FVC ratio.

(2) Safety: presence or absence of complications.

\section{Procedure:}

The procedure was done in the bronchoscopy unit, Chest Medicine Department, Mansoura University Hospital using fiberoptic bronchoscope under conscious sedation. The bronchoscope was introduced to just below the targeted segmental bronchus that was previously determined by high resolution CT chest. A balloon catheter was introduced into the targeted segmental bronchus with the tip positioned 3 to $4 \mathrm{~cm}$ further than the end of the bronchoscope.

After inflation of the balloon, the biological agent (30 $\mathrm{ml}$ autologous blood) was injected via the catheter over 10 to 15 seconds and left in position for 3-6 minutes allowing time for blood to coagulate. The bronchoscope was then repositioned at the following targeted segment.

\section{RESULTS}

This study included seven male patients with sever to very severe COPD.

Table (1): Age and COPD grouping according to GOLD (2013)

\begin{tabular}{lcc}
\hline & Age(Years) (mean \pm SD) & $55.71 \pm 4.03$ \\
\hline COPD group [N (\%)] & GOLD III & $1(14.3 \%)$ \\
& GOLD IV & $6(85.7 \%)$ \\
\hline
\end{tabular}

Patients had severe to very severe airflow obstruction based on GOLD classification. 
Table (2): Baseline assessment of spirometric measures, residual volume, residual volume/ total lung capacity ratio (RV/TLC).

\begin{tabular}{cc}
\hline RV/TLC\% (mean \pm SD) & $154 \pm 23$ \\
\hline FEV1 (\% Predicted) (mean \pm SD) & $26 \pm 4$ \\
\hline FEV1/FVC\% (mean \pm SD) & $50 \pm 8$ \\
\hline RV $(\%$ Predicted) (mean \pm SD) & $122 \pm 12$ \\
\hline
\end{tabular}

\section{Efficacy Results:}

\section{A) Primary outcome:}

$\square$ RV/TLC:

Table (3): Changes in RV/TLC after 12 weeks.

\begin{tabular}{ccc}
\hline Baseline & 12 weeks & $\begin{array}{c}P^{*} \\
\text { value }\end{array}$ \\
\hline $154 \pm 23$ & $125 \pm 20$ & 0.038 \\
\hline
\end{tabular}

There was statistically significant reduction in RV/TLC $(p=0.038)$

B) Secondary outcomes:

\section{$\square$ Spirometric measures:}

Table (4): Changes in post-bronchodilator FEV1and FEV1/FVC after 12weeks:

\begin{tabular}{clll}
\hline & Baseline & 12 weeks & $\begin{array}{l}\text { P* } \\
\text { value }\end{array}$ \\
\hline FEV1(\% Predicted) & $26 \pm 4$ & $34 \pm 5$ & 0.018 \\
\hline FEV1/FVC \% & $50 \pm 8$ & $66 \pm 10$ & 0.003 \\
\hline FEV1 significantly increased after & 12 & weeks post procedure $(p=0.018)$. There was
\end{tabular}
significant improvement in FEV1/FVC $\%(p=0.003)$.

Safety results (presence or absence of complications).

All cases tolerated the procedure with no mortality. There was one case developed pneumonia at the same side of intervention 10 days post procedure (incidence: $14.3 \%$ ) that was improved by 10 days course of antibiotic and two cases developed mild haemoptysis (blood streaked sputum) (incidence: 28.5\%). No life threatening complications e.g (pneumothorax, pulmonary embolism, cardiac ischaemia or myocardial infarction) occurred.

\section{DISCUSSION}

\section{A) Primary outcome:}

\section{$\square R$ R/TLC:}

In our study there was statistically significant reduction in RV/TLC at 12 weeks post procedure compared to baseline values. These results were in agreement with the first study related to biological lung volume reduction performed by Reilly et al. ${ }^{3}$ who used fibrin hydrogel. Efficacy data demonstrated significant decrease in $\mathrm{RV} / \mathrm{TLC}$.

Herth et al. ${ }^{4}$ were the first who assessed the safety and efficacy of polymeric lung volume reduction (PLVR) using AeriSeal in treatment of advanced heterogenous emphysema. Regarding the outcome measure RV/TLC, there were more favorable results in heterogeneous than in homogenous emphysema.

B) Secondary outcomes:

As regard spirometric measures outcomes, in our study, FEV1\% significantly increased after 12 weeks post procedure $(\mathrm{p}=0.018)$. In addition, we found significant improvement in FEV1/FVC \% at 12 weeks post procedure compared to baseline values $(\mathrm{p}=0.003)$. These results were in parallel to those found by Refaely et al. ${ }^{5}$ and Criner et al. ${ }^{2}$ (2009) where there was significant improvement in the same parameters.

\section{C) Posttreatment Complications}


In our study, no deaths were encountered. Pneumonia occurred in one case at the same side of intervention 10 days post procedure (incidence: $14.3 \%$ ) that was improved after 10 days of inpatient treatment. This ratio appear to be much higher than that found by Criner et al. ${ }^{6}$ who reported one case of pneumonia (evaluated in emergency room) out of 28 (incidence: $3.5 \%$ ) There were no other serious complications observed during the study.

\section{CONCLUSION}

Bronchoscopic lung volume reduction using autologous blood injection could be an effective and cheap method to treat advanced emphysema in comparison to other agents used in the clinical trials with a relatively safe profile.

\section{REFERENCES}

1. Sardenberg RA, Younes RN, Deheizelin D: Lung volume reduction surgery: an overview. Rev Assoc Med Bras 2010, 56(6): 719-23.

2. Criner GJ, Pinto-Plata V, Strange C, Dransfield M, Gotfried M, Leeds W, McLennan G, Refaely Y, Tewari S, Krasna
M, et al. Biologic lung volume reduction in advanced upper lobe emphysema: phase 2 results. Am J Respir Crit Care Med 2009; 179: 791-798.

3. Reilly J, Washko G, Pinto-Plata V, Velez E, Kenney L, Berger R, Celli B. Biological lung volume reduction: a new bronchoscopic therapy for advanced emphysema. Chest 2007; 131: 1108-1113.

4. Herth FJ, Gompelmann D, Stanzel F, Bonnet R, Behr J, Schmidt B, Magnussen H, Ernst A, Eberhardt R. Treatment of advanced emphysema with emphysematous lung sealant (AeriSeal@). Respiration 2011; 82: 36-45.

5.Refaely $Y$, Dransfield M, Kramer MR, Gotfried M, Leeds W, McLennan G, Tewari S, Krasna M, Criner GJ. Biologic lung volume reduction therapy for advanced homogeneous emphysema. Eur Respir J 2010; 36: 20-27.

6. Criner G, Sternberg AL. National Emphysema Treatment Trial: the major outcomes of lung volume reduction surgery in severe emphysema. Proc Am Thorac Soc 2008; 5: 393-405. 